\title{
Thoracoscopic surgical management of esophageal benign tumor
}

\author{
HW Jeon*, SW Sung, JK Park, H Song \\ From 23rd World Congress of the World Society of Cardio-Thoracic Surgeons \\ Split, Croatia. 12-15 September 2013
}

\section{Background}

Benign esophageal tumors are rare; complete surgical resection is essential for the management of the submucosal tumors. Larger, symptomatic, or non-diagnostic lesions should be resected for both diagnostic and therapeutic indications. VATS has become a popular treatment in the thoracic surgery, however thoracoscopic esophageal surgery may lead to increased operative complications. We evaluated the effect and safety of thoracoscopic surgery foe esophageal submucosal lesions..

\section{Methods}

A retrospective study evaluated patients undergoing thoracoscopic treatment of benign submucosal tumors. Between March 2011 and Feburary 2013, 16 patients underwent thoracoscopic resection of benign submucocal tumors. Intraoperative esophagoscopy was performed for tumor localization by transillumination and confirmation of mucosal integrity after enucleation in every patient.

\section{Results}

Median patient age was 46.5 years (range $30-56$ ). The median surgery time was 167.5 minutes (range: $80-429$ ). The median tumor size was $3.65 \mathrm{~cm}$ (range 1.3-9). The median hospital stay was 4 days (range 2-12). There were 15 leiomyoma 1 neurogenic tumor. There was one case of conversion to thoracotomy due to residual tumor after enucleation by esophagoscopy. Mucosal injuries occurred in three patients, two accindentally and one intentionally; each patient was treated with primary repair and confirmed integrity with flexible gastroscopy. We could localize the small tumor in four patients with esophagoscopy. Esophagoscopic assistance was necessary in eight patients

\footnotetext{
* Correspondence: ulnazoro@catholic.ac.kr

Thoracic and Cardiovascular Department, Bucheon St. Mary's Hospital, Bucheon, Republic of Korea
}

C 2013 Jeon et al; licensee BioMed Central Ltd. This is an Open Access article distributed under the terms of the Creative Commons Attribution License (http://creativecommons.org/licenses/by/2.0), which permits unrestricted use, distribution, and reproduction in any medium, provided the original work is properly cited.
Cite this article as: Jeon et al:: Thoracoscopic surgical management of esophageal benign tumor. Journal of Cardiothoracic Surgery 2013 8(Suppl 1):O258. to have better idea where to make myotomy. There were no major morbidities such as postoperative leakage or mortality.

\section{Conclusion}

Esophagela submucosal tumors can be treated safely with thoracoscopic surgery. However intraoperative esophagoscopy allows more accurate tumor localization and direction of esophageal access incision and decreases complications during VATS enucleation of esophageal submucosal tumors.

Published: 11 September 2013

Submit your next manuscript to BioMed Central and take full advantage of:

- Convenient online submission

- Thorough peer review

- No space constraints or color figure charges

- Immediate publication on acceptance

- Inclusion in PubMed, CAS, Scopus and Google Scholar

- Research which is freely available for redistribution 